\title{
Stress and Its Association with Health and Well Being
}

\author{
Kamble $\mathrm{J}^{1 *}$, Pathak $\mathrm{A}^{2}$
}

\section{ABSTRACT}

The gender gap is persistent across areas of health in our society, irrespective of poor- rich, caste, religion and geographical areas. The objective of the present study is to understand the effect of gender and age differences on the stress, health and well-being. The sample consisted of 100(50Male and 50-Female). These two groups male and female were further into two groups' i.e. younger group and older group. Each group comprises 25 males and 25 female. The respondents were assessed on Stress Scale, PGI- Health questionnaire and General Well-Being Measure. On ANOVA, the results showed significant effect of gender as well as age on the measure of well being and interaction effect showed significant effect. Younger group have more stress than older group. On Well-Being, the results showed female and older group has better well being than male and younger group.

Keywords: Stress, Health, Well Being

Modern life is full of hassles, deadlines, frustrations, and demands. For many people, stress is so commonplace that it has become a way of life. Stress isn't always bad. In small doses, it can help you perform under pressure and motivate you to do your best. But when you're constantly running in emergency mode, your mind and body pay the price. You can protect yourself by recognizing the signs and symptoms of stress and taking steps to reduce its harmful effects.

\section{What is stress?}

Selye (1956) stress is "any external event or internal drive which threatens to upset the organism equilibrium". Stress is a common problem that affects almost all of us at some point in our lives. Learning to identify when you are under stress, what is stressing you, and different ways of coping with stress can greatly improve both your mental and physical well being.

\footnotetext{
${ }^{1}$ M. Phil. Clinical Psychology 2nd year IBS, GFSU Gandhinagar, Gujarat

${ }^{2}$ Clinical Psychologist, IBS, GFSU Gandhinagar, Gujarat

*Responding Author

(C) 2016 I J Kamble, A Pathak; licensee IJIP. This is an Open Access Research distributed under the terms of the Creative Commons Attribution License (http://creativecommons.org/licenses/by/2.0), which permits unrestricted use, distribution, and reproduction in any Medium, provided the original work is properly cited.
} 


\section{Signs and symptoms of stress overload}

The following table lists some of the common warning signs and symptoms of stress. The more signs and symptoms you notice in yourself, the closer you may be to stress overload.

Stress Warning Signs and Symptoms

\section{Cognitive Symptoms}

- Memory problems

- Inability to concentrate

- Poor judgment

- Seeing only the negative

- Anxious or racing thoughts

- Constant worrying

\section{Physical Symptoms}

- Aches and pains

- Diarrhea or constipation

- Nausea, dizziness

- Chest pain, rapid heartbeat

- Loss of sex drive

- Frequent colds

\section{Emotional Symptoms}

- Moodiness

- Irritability or short temper

- Agitation, inability to relax

- Feeling overwhelmed

- Sense of loneliness and isolation

- Depression or general unhappiness

Behavioral Symptoms

- Eating more or less

- Sleeping too much or too little

- Isolating yourself from others

- $\quad$ Procrastinating or neglecting responsibilities

- Using alcohol, cigarettes, or drugs to relax

- $\quad$ Nervous habits (e.g. nail biting, pacing)

\section{Health}

WHO (2001) defines health as "a state of complete physical, mental and social wellbeing and merely the absence of disease and infirmity”. Psychological health:- Psychological Health is the psychological state of someone who is functioning at a satisfactory level of emotional and behavioral adjustment. Physical health:- Physical Health is the condition of your body. And it is essential part for overall health of an individual.

\section{Well-Being}

Well-being is a positive outcome that is meaningful for people and for many sectors of society, because it tells us that people perceive that their lives are going well. Good living conditions (e.g., housing, employment) are fundamental to well-being. "Well-being generally includes global judgments of life satisfaction and feelings ranging from depression to joy. Well-being is associated with numerous health-, job-, family-, and economically-related benefits.

\section{REVIEW OF LITERATURE:-}

Elly Robinson and Rennell Adams,(2008) conducted a study on "Housing stress and the mental health and wellbeing of families”. According to them the study regarding housing affordability and associated housing stress in Australia, more research is needed to better define the relationship between housing and health, particularly mental health. However, it seems important for family and relationship service providers to recognize housing issues as being 
possible underlying problems that place considerable stress on families, including their health and wellbeing

> Frances M. McKee-Ryan, et al."' (2005) done study on "Psychological and Physical WellBeing During Unemployment: A Meta-Analytic Study" The finding of the study show that unemployed individuals had lower psychological and physical well-being than did their employed counterparts. Unemployment duration and sample type (school leaver vs. mature unemployed) moderated the relationship between mental health and unemployment, but the current unemployment rate and the amount of unemployment benefits did not. Within unemployed samples, work-role centrality, coping resources (personal, social, financial, and time structure), cognitive appraisals, and coping strategies displayed stronger relationships with mental health than did human capital or demographic variables. The authors identify gaps in the literature and propose directions for future unemployment research.

$>\quad$ Ajay K. JainandSabir I. Gigaet al (2013) conducted study on "Stress, Health and WellBeing: The Mediating Role of Employee and Organizational Commitment The results of this study suggest that employee commitment to their organization and their perceptions of employer commitment to them have controlled the negative impact of organizational stressors on their health and well-being.

$>\quad$ C.M. Aldwin , L.A. Yancura et al . (2010) studied the "Effects of stress on health and aging: Two paradoxes." Findings of this study suggest that although older adults are thought to experience more stress and to be more vulnerable to its adverse effects, they often report less stress than younger adults and sometimes show more resilience. Paradoxically, while stress sometimes has long-term positive effects on well-being, studies differ as to whether this increases or decreases with age. The conclusion is that older individuals have learned to appraise and cope differently with stress. This protects them in spite of their increased physiological vulnerability and may also increase the possibility of stress-related growth and optimal aging.

$>\quad$ Benjawan Tawatsupa et al,(2012) conducted study on""Heat stress, health and well-being: findings from a large national cohort of Thai adults". Findings show that the negative health and well-being outcomes (low-energy level, emotional problems and low life satisfaction) associated with increasing frequency of heat stress interfering with daily activities.

\section{METHODOLOGY}

\section{Objectives}

1) To examine the stress and well-being among youth and old age.

2) To examine stress and health among youth and old age.

3) To examine health and well-being among youth and old age.

4) To study the gender (male and female) and age differences (18-38 and 40-60) with respect to stress, health and well-being.

\section{Sample:-}

The sample consisted of 100 respondents (50-Male and 50-Female) of Bhopal City. These two groups (male and female) were further divided into two groups i.e. 18-38 years (younger group) 
and 40-60 years(older group). Each group comprises (25 males and 25 females) Sample. They were tested individually.

\section{Tools used:-}

In present investigation three important measures was used. The details of these tools in brief are given below:-

1. Stress scale:-The Holmes and Rahe stress scale is a list of 43 stressful life events that can contribute to illness.0-149 no significant problem, 150-199 mild stress, 35\% chance of illness or health change, 200-299 moderate stress 50\% chance of illness or health change, 300+ major stress $80 \%$ chance of illness or health change.

2. PGI- General Health Questionnaire:- It was develop by Verma, Wig and Pershad (1985). This scale is comprised of 38 items including part A \& B. Apart (physical distress) of the scale consist of 16 items and B part(psychological distress) consist 22 items. For scoring of this scale the number of ticks on section $\mathrm{A}$ and $\mathrm{B}$. The test-retest and spilt-half reliability was found to be 0.88 and 0.86 respectively and validity of this scale is found highly satisfactory.

3. PGI General Well Being Measure (PGI-GWBM):- This scale was develop by S.K. Verma and Amita Verma. This scale consists of 20 items and the subjects had to respond in Yes or No against each item.

\section{Design:-}

A Cross-sectional between group design was used.

\section{Statistical Analysis:-}

SPSS was used for statistical analysis Mean, S.D., Frequency calculated. A 2x 2 ANOVA was used.

\section{Procedure :}

For the purpose of the study, subjects were selected and conducted by taking prior appointment. Rapport was established with each of the subjects and all the query regarding the study were answer. They were assured that the information would be kept confidential and used only for academic purpose. Those who gave consent for the participation were included in the study. The questionnaires were collected as per the convenience. 
RESULT AND DISCUSSION

Table No.-1 Socio Demographic Detail

\begin{tabular}{|l|l|l|l|l|l|}
\hline \multicolumn{2}{|l|}{} & Frequency & Percentage & $\begin{array}{l}\text { Valid } \\
\text { Percent }\end{array}$ & $\begin{array}{l}\text { Cumulative } \\
\text { Percent }\end{array}$ \\
\hline Age & $18-38$ & 50 & 50.0 & 50.0 & 50.0 \\
& $40-60$ & 50 & 50.0 & 50.0 & 50.0 \\
& Total & 100 & 100.0 & 100.0 & 100.0 \\
\hline Gender & Male & 50 & 50.0 & 50.0 & 50.0 \\
& Female & 50 & 50.0 & 50.0 & 50.0 \\
& Total & 100 & 100.0 & 100.0 & 100.0 \\
\hline \multirow{5}{*}{ Education } & 10 to 12 & & & & \\
& Graduate & 9 & 9.0 & 9.0 & 9.0 \\
& Post graduate & 17 & 74.0 & 74.0 & 74.0 \\
\hline SES & Total & 100 & 17.0 & 17.0 & 17.0 \\
& Lower & 0 & 0.0 & 100.0 & 100.0 \\
\hline & Middle & 82 & 82.0 & 0.0 & 0.0 \\
& Higher & 18 & 18.0 & 82.0 & 82.0 \\
& Total & 100 & 100.0 & 18.0 & 18.0 \\
\hline Occupation & Student & 33 & 33.0 & 100.0 & 100.0 \\
& Working & 36 & 36.0 & 33.0 & 33.0 \\
& Non-working & 31 & 31.0 & 36.0 & 36.0 \\
& Total & 100 & 100.0 & 100.0 & 31.0 \\
& & & & 100.0 \\
\hline
\end{tabular}

The above frequency table shows that the 50 from younger group and 50 from older group. Out of 100,50 are male and 50 are female. 9 people studied till $12^{\text {th }}$ class, 74 people studied till graduation and 17 people studied till post-graduation. No one fall under lower economic status. 82 people are from middle economic status and 18 people belong to higher economic status. 33 people are students, 36 are working and 31 are non-working. A study on Socioeconomic status and health behaviors in adolescence: a review of the literature ( Handson ED, et al ) concluded that, there is some associations between SES and health behaviors exist during adolescence, the associations are not as robust as those in adulthood. Efforts to curb poor diet, inactivity, and smoking behaviors should target low SES adolescents, whereas efforts to curb teen drinking and marijuana use may be useful across the SES spectrum. The relations of socioeconomic status to health status, health behaviors in the elderly (Lee SG et al) concluded that the SES and health status, those with a low SES had poorer subjective health states and lower satisfaction about their physical health. Also, acute disease experiences, admission rates and tooth desideration rates were higher in those of low SES. In the view of physical and cognitive functions, the ADL, IADL and MMSE-K scores were also lower in those of low SES. From these findings, we surmise that those with low SES have a poorer health condition and less money to spend on health, therefore, they can not smoke or drink alcohol, exercise and or have a physical health check-up. 
Table no. 2. Mean and SD

Table No. 2 (a)Means of Stress t, GWBM, Health t, Physical health Psychological health * age

\begin{tabular}{|l|l|l|l|l|l|l|}
\hline \multicolumn{2}{|l|}{ Age } & Stress t & GWBM & Health t & $\begin{array}{l}\text { Physical } \\
\text { health }\end{array}$ & Psychological health \\
\hline \multirow{4}{*}{$\begin{array}{l}18-38 \\
\text { yrs }\end{array}$} & Mean & 194.1600 & 11.9200 & 8.1200 & 4.0800 & 4.0000 \\
\cline { 2 - 7 } & N & 50 & 50 & 50 & 50 & 50 \\
\hline \multirow{4}{*}{$\begin{array}{l}\text { Std. } \\
\text { Deviation } \\
\text { yrs }\end{array}$} & 73.55974 & 5.13428 & 5.25139 & 2.57016 & 2.77010 \\
\cline { 2 - 7 } & Mean & 152.9600 & 12.7800 & 6.8200 & 3.5400 & 3.2800 \\
\hline \multirow{4}{*}{ Total } & $\begin{array}{l}\text { Std. } \\
\text { Deviation }\end{array}$ & 66.15010 & 5.19925 & 4.95980 & 2.47609 & 2.53981 \\
\cline { 2 - 7 } & Mean & 173.5600 & 12.3500 & 7.4700 & 3.8100 & 3.6400 \\
\cline { 2 - 7 } & $\begin{array}{l}\text { Std. } \\
\text { Deviation }\end{array}$ & 72.61304 & 5.15884 & 5.12363 & 2.52541 & 2.66864 \\
\hline
\end{tabular}

The above result shows that Mean and SD of younger group have more stress than old group. And their well-being results also show is affected, and their health also becomes low. And both physical and psychological health affected in younger group than older group. The study on Gender and Age Differences in the Development of Hope Post Stressful Life, (Aundreah Walenski, et al ). The purpose of this study is to examine how current age and the age when the event occurs influences agency and pathway. And concluded that the determined no differences between age and age of when the stressful life event occurred. However, when men and women were analyzed separately, men exhibited differences in hope agency among age of when the stressful life event occurred.

Table No. 2(b) Stress t, GWBM, Health t, Physical health, Psychological health * Gender

\begin{tabular}{|l|l|l|l|l|l|l|}
\hline \multicolumn{2}{|l|}{ Gender } & Stress t & GWBM & Health t & Physical health & Psychological health \\
\hline \multirow{4}{*}{ male } & Mean & 179.2400 & 12.0200 & 7.6200 & 4.0000 & 3.6200 \\
\cline { 2 - 7 } & $\mathrm{N}$ & 50 & 50 & 50 & 50 & 50 \\
\cline { 2 - 7 } & $\begin{array}{l}\text { Std. } \\
\text { Deviation }\end{array}$ & 71.57971 & 5.41159 & 5.36006 & 2.61861 & 2.82041 \\
\hline \multirow{4}{*}{ female } & Mean & 167.8800 & 12.6800 & 7.3200 & 3.6200 & 3.6600 \\
\cline { 2 - 7 } & $\mathrm{N}$ & 50 & 50 & 50 & 50 & 50 \\
\cline { 2 - 7 } & $\begin{array}{l}\text { Std. } \\
\text { Deviation }\end{array}$ & 73.91491 & 4.92573 & 4.92573 & 2.44022 & 2.53635 \\
\hline \multirow{3}{*}{ Total } & Mean & 173.5600 & 12.3500 & 7.4700 & 3.8100 & 3.6400 \\
\cline { 2 - 7 } & $\begin{array}{l}\text { Std. } \\
\text { Deviation }\end{array}$ & 72.61304 & 5.15884 & 5.12363 & 2.52541 & 2.66864 \\
\hline
\end{tabular}


The above result of Mean and SD show that male have more stress than female. And well-being and health is also affected in male than female. A study on age differences in stress, social resources and well-being in middle and older age( Mike Martin, et al, 8,2015), concluded that there is considerable support for a link between interrelationships among the constructs of social resources, stress, and well-being in middle-aged and older adults. The results indicate higher levels of health-related stress and similar levels of social resources in the older group. There was a strong effect of stress on well-being, no direct effect of social resources on well-being, and a mediating effect of stress on well-being. The relative contributions of stress and resources to well-being were comparable between age groups.

Table no. 2(c) Stress t, GWBM Health t, Physical health, Psychological health * Education

\begin{tabular}{|c|c|c|c|c|c|c|}
\hline \multicolumn{2}{|l|}{ Education } & Stress $\mathbf{t}$ & GWBM & Health t & Physical health & Psychological health \\
\hline \multirow{3}{*}{10 to 12 class } & Mean & 170.8889 & 13.2222 & 6.7778 & 3.2222 & 3.6667 \\
\hline & $\mathrm{N}$ & 9 & 9 & 9 & 9 & 9 \\
\hline & $\begin{array}{l}\text { Std. } \\
\text { Deviation }\end{array}$ & 57.50749 & 3.49205 & 3.49205 & 1.85592 & 1.50000 \\
\hline \multirow{3}{*}{ Graduate } & Mean & 170.1216 & 12.3514 & 7.4054 & 3.8649 & 3.5405 \\
\hline & $\mathrm{N}$ & 74 & 74 & 74 & 74 & 74 \\
\hline & \begin{tabular}{|l|} 
Std. \\
Deviation \\
\end{tabular} & 74.17103 & 5.43815 & 5.39131 & 2.63446 & 2.82450 \\
\hline \multirow{3}{*}{ post graduate } & Mean & 189.9412 & 11.8824 & 8.1176 & 3.8824 & 4.0588 \\
\hline & $\mathrm{N}$ & 17 & 17 & 17 & 17 & 17 \\
\hline & $\begin{array}{l}\text { Std. } \\
\text { Deviation }\end{array}$ & 74.34587 & 4.79430 & 4.79430 & 2.42080 & 2.51174 \\
\hline \multirow{3}{*}{ Total } & Mean & 173.5600 & 12.3500 & 7.4700 & 3.8100 & 3.6400 \\
\hline & $\mathrm{N}$ & 100 & 100 & 100 & 100 & 100 \\
\hline & \begin{tabular}{|l|} 
Std. \\
Deviation
\end{tabular} & 72.61304 & 5.15884 & 5.12363 & 2.52541 & 2.66864 \\
\hline
\end{tabular}

The above result shows that post graduate group has more stress than graduate and $12^{\text {th }}$ class people. And the well-being of post graduate people also affected. Because of these their health is affected. 
Stress and Its Association with Health and Well Being

Table No. 2 (d) Stress t, Gwbm, Health t, Physical health Psychological health * SES

\begin{tabular}{|l|l|l|l|l|l|l|}
\hline \multicolumn{2}{|l|}{ SES } & Stress t & GWBM & Health t & Physical health & Psychological health \\
\hline \multirow{4}{*}{ middle } & Mean & 169.7561 & 12.4634 & 7.3171 & 3.7805 & 3.5488 \\
\cline { 2 - 7 } & N & 82 & 82 & 82 & 82 & 82 \\
\cline { 2 - 7 } & $\begin{array}{l}\text { Std. } \\
\text { Deviation }\end{array}$ & 70.08576 & 5.22387 & 5.17563 & 2.56291 & 2.67661 \\
\hline \multirow{4}{*}{ higher } & Mean & 190.8889 & 11.8333 & 8.1667 & 3.9444 & 4.0556 \\
\cline { 2 - 7 } & N & 18 & 18 & 18 & 18 & 18 \\
\cline { 2 - 7 } & $\begin{array}{l}\text { Std. } \\
\text { Deviation }\end{array}$ & 83.14685 & 4.96162 & 4.96162 & 2.41252 & 2.66728 \\
\hline \multirow{3}{*}{ Total } & Mean & 173.5600 & 12.3500 & 7.4700 & 3.8100 & 3.6400 \\
\cline { 2 - 7 } & N & 100 & 100 & 100 & 100 & 100 \\
\cline { 2 - 7 } & $\begin{array}{l}\text { Std. } \\
\text { Deviation }\end{array}$ & 72.61304 & 5.15884 & 5.12363 & 2.52541 & 2.66864 \\
\hline
\end{tabular}

The above result shows that stress is more in higher SES than middle SES group. The general well-being of higher SES group is better may be because they enjoy better facilities and comforts in their life than middle group. And the health is also affected in higher group because of stress. The study on the relation on socioeconomic status to health status, health behavior in the elderly (SoK-Goo Lee, So-Youn Jeon,2005). The study concluded that the socioeconomic status play an important role in health behavior and status in the elderly. Low socioeconomic status brings about unhealthy behavior and poor health status in the elderly people. Therefore more specific target ( esp., Low socioeconomic status person) health promotion activities for the elderly are very important to improve not only health status, but their health inequality also.

Table No. 2 (e) Stress t, Gwbm, Health t, Physical health Psychological health * Occupation

\begin{tabular}{|l|l|l|l|l|l|l|}
\hline Occupation & Stress t & GWBM & Health t & Physical health & Psychological health \\
\hline \multirow{4}{*}{ Student } & Mean & 151.8485 & 13.7879 & 6.2121 & 3.1212 & 3.0303 \\
\cline { 2 - 7 } & $\mathrm{N}$ & 33 & 33 & 33 & 33 & 33 \\
\cline { 2 - 7 } & $\begin{array}{l}\text { Std. } \\
\text { Deviation }\end{array}$ & 21.96463 & 4.16652 & 4.16652 & 2.10294 & 2.15762 \\
\hline \multirow{5}{*}{ Working } & Mean & 236.8056 & 10.3889 & 9.6667 & 4.9167 & 4.7500 \\
\cline { 2 - 7 } & $\mathrm{N}$ & 36 & 36 & 36 & 36 & 36 \\
\hline \multirow{4}{*}{$\begin{array}{l}\text { Std. } \\
\text { Den- }\end{array}$} & Meviation & 78.50016 & 5.49949 & 5.63661 & 2.70845 & 2.98927 \\
\hline \multirow{4}{*}{ Total } & $\mathrm{N}$ & 123.2258 & 13.0968 & 6.2581 & 3.2581 & 3.0000 \\
\cline { 2 - 7 } & $\begin{array}{l}\text { Std. } \\
\text { Deviation }\end{array}$ & 41.94418 & 5.15335 & 4.69019 & 2.33763 & 2.40832 \\
\cline { 2 - 7 } & Mean & 173.5600 & 12.3500 & 7.4700 & 3.8100 & 3.6400 \\
\cline { 2 - 7 } & $\begin{array}{l}\text { Std. } \\
\text { Deviation }\end{array}$ & 72.61304 & 5.15884 & 5.12363 & 2.52541 & 2.66864 \\
\hline
\end{tabular}


The above result shows that the working people have more stress than non-working and student. The general well being of non-working and student is better than working. Health is also affected in working than non-working and student. In non working group generally housewife and old age people came. So because that they have less stress. And students also do not having very high of stress because they may be enjoying their college life and they don't have many responsibility like working people. In working group most of the participants are married. The study on gender differences in stress, satisfaction and mental well-being among general well being practitioners in England(U. Rout,1999). This paper attempt to compare job stress, job satisfaction and mental well-being of male and female general practitioners. The study concluded that the female general practitioners showed positive sign of mental well being contrast with a normative group. Conversely, male doctors showed more anxiety and depression. There was no significant difference between male and female general practitioners in the job satisfaction scale both gender were unhappy about their rates of pay, hours of work and amount of work they do.

Table No. 3. ANOVA

Table No. 3(a) 2×2 ANOVA For Stress

\begin{tabular}{|l|l|l|l|l|}
\hline $\begin{array}{l}\text { Source of } \\
\text { variation }\end{array}$ & SS & df & MS & F \\
\hline A(Gender) & 2714302.86 & 1 & 2714302 & $5483 * *$ \\
\hline B (Age group) & 1700612.68 & 1 & 1700612.7 & $345^{* *}$ \\
\hline AB & -1656792 & 1 & -1656792 & $-3347^{* *}$ \\
\hline Within Group & 474973.56 & 96 & 494.7 & \\
\hline Total & 3233097.1 & 99 & & \\
\hline
\end{tabular}

The summary of 2-way ANOVA is used, shown in Table no.3 (a) .It showed that the main effect of gender, $\mathrm{F}(1,96)=5483, \mathrm{p}<0.0$.The main effect of age group was significant, $\mathrm{F}(1,96)=$ $345, p<0.01$. The interaction of gender and age group was significant, $F(1,36)=-3347, p<0.01$. The study on investigated the age and gender effects on perceived interpersonal stress, coping with interpersonal stressors, and adjustment among early and middle adolescents (Hampel \& Petermann et al ,2006),results of this study indicate that Fifth graders scored lower on maladaptive coping strategies and externalizing problems and reported more adaptive coping strategies than sixth and seventh graders. Compared with boys, girls evaluated a higher amount of perceived interpersonal stress and used more social support. Furthermore, girls scored higher on maladaptive coping strategies and emotional distress and scored lower on distraction than boys. 
Stress and Its Association with Health and Well Being

Table no. 3 (b) $2 \times 2$ ANOVA For Health

\begin{tabular}{|l|l|l|l|l|}
\hline $\begin{array}{l}\text { Source of } \\
\text { variation }\end{array}$ & SS & df & MS & F \\
\hline A(Gender) & 20.24 & 1 & 20.24 & $7.78^{* *}$ \\
\hline B (Age group) & 42.24 & 1 & 42.24 & $16.3^{* *}$ \\
\hline AB & 68.9 & 1 & 68.9 & $27^{* *}$ \\
\hline Within Group & 2502.52 & 96 & 2.60 & \\
\hline Total & 2615.9 & 99 & & \\
\hline
\end{tabular}

The summary of 2-way ANOVA is used, shown in Table no.3( b ). It showed that the main effect of gender, $\mathrm{F}(1,96)=0.86, \mathrm{p}<0.01$. The main effect of age group was significant, $\mathrm{F}(1,96)=$ $16.3, \mathrm{p}<0.01$. The interaction of gender and age group of health was significant, $F(1,36)=27$ , $\mathrm{p}<0.01$. The study on Gender differences in health information behaviour: a Finnish populationbased survey,(Stefan Ek' et al) the results show that women were more interested in and reported much more active seeking of health-related information, paid more attention to potential worldwide pandemics and were much more attentive as to how the goods they purchase in everyday life affect their health than men did. Women also reported receiving far more informal health-related information from close family members, other kin and friends/workmates than men did. Thus, to succeed in public health promotion and interventions the measures taken should be much more sensitive to the gender gap in health information behaviour.

Table no. 3 (c) $2^{\times} 2$ ANOVA For Well-being

\begin{tabular}{|l|l|l|l|l|}
\hline $\begin{array}{l}\text { Source of } \\
\text { variation }\end{array}$ & SS & df & MS & F \\
\hline A(Gender) & 13738 & 1 & 13738 & $508.3^{* *}$ \\
\hline B (Age group) & 13746 & 1 & 13746 & $509^{* *}$ \\
\hline AB & -13617 & 1 & -13617 & $-504^{* *}$ \\
\hline Within Group & 2595.1 & 96 & 27.03 & \\
\hline Total & 16462.1 & 99 & & \\
\hline
\end{tabular}

The summary of 2-way ANOVA is used, shown in Table no.3( c ) . It showed that the main effect of gender, $F(1,96)=5483, p<0.01$. The main effect of age group was significant, $F(1,96)=$ $345, \mathrm{p}<0.01$. The interaction of gender and age group of well-being was significant, $F(1,36)=$ $504, \mathrm{p}<0.01$. The study on Subjective well-being as a function of age and gender: A multivariate look for differentiated trends (Dov Shmotkin, et al.), concluded that the results indicate the differential impact of personal variables on the aspects of SWB. Refering to the Israeli context, it seems that both cohort- and aging-related variables account for the decline of life satisfaction in the older subjects. Age-associated decline of affect is apparently connected to some other adaptive mechanisms, which regulate both positive and negative affect in old age. 


\section{CONCLUSION}

The result showed in age wise Mean and SD, that the younger group have more stress than older group. And in gender wise Mean and SD, male have more stress than female group. On Anova, there is a significant effect on gender and age group. And there is a interaction among the two group.

\section{Acknowledgement}

I am deeply indebted my parents who help me in data collection and immense support for completion in my research work. And the special gratitude to community in charge who give permission to collecting data.

\section{REFERENCES}

A study on age differences in stress, social resources and well-being in middle and older age (Milke Martin, et al, 8, 2015) Journal of Gerontology: Psychological Sciences 2001 Vol-56 B, no. 4, pg 214-222.

Ajay K. JainandSabir I. Gigaet al.(2013) "Stress, Health and Well-Being: The Mediating Role of Employee and Organizational Commitment, International Journal Of Environmental Research and Public Health, Vol 10, issue 10, doi:10.3390/ijerph10104907 October 2013.

C.M. Aldwin , L.A. Yancura et al ."Effects of stress on health and aging: Two paradoxes." California Agriculture 64(4):183-188. DOI: 10.3733/ca.v0l 64 n0 4 p183. OctoberDecember 2010.

Elly Robinson and Rennell Adams, (June 2008)“Housing stress and the mental health and wellbeing of families”, the Australian Institute of Family Studies,.9 pp. ISSN: 1834-2434

Frances M. McKee-Ryan, et al.(2005) "Psychological and Physical Well-Being During Unemployment: A Meta-Analytic Study “,(2005), Journal of Applied Psychology, 2005, Vol. 90, No. 1, 53-76

Garry L. Martin. Et al. (1988), 'Psychology, Adjustment And Everyday Living', 2nd Edition, Published by Prentice Hall.

Gender differences in health information behavior: a finish population-based survey. Health Promotion International , Stefen EK, et. al, 2015, sep. 30(3), 736-45. doi:10:1093/heapro/dat063. Epub. 2013 Aug 28.

Gender differences in stress, satisfaction and mental well-being among general wellbeing practitioners in England. (U. Rout,1999) Psychology Health and Medicine, Vol. 4, Issue 4, 19 Aug 1999, pg 345-354.

Melinda Smith, M.A., Robert Segal, M.A., and Jeanne Segal, Ph.D. “ Stress symptoms, sign and Causes. The Effect Of Stress Overload". HelpGuide.Org(http://www.helpguide.org/articles/stress/stress-symptoms-causes-andeffects.htm)

Selye, H. The Stress of Life, McGraw-Hill, New York, published in March 1978, and first published in 1956 . 
Socio economic status and health behaviors in adolescence: a review of the literature. Hanson MD, et al., Journal of behavioral medicine 2007, jun, 30 (3), 263-285, Epub. 2007 May 20.

Subjective well-being as a function of age and gender: A multivariate look for differential trends, Dovshmotkin, et al. Social Indicators Research. Nov. 1990, Vol. 23, issue 3, 201230.

The relation of socio economic status to health status, health behaviors in the elderly (Lee SG et al.) Journal of Preventive Medicine Public Health, 2005 May; 38 (2): 154-162.

The study on investigated the age and gender effect on perceived interpersonal stress, coping with interpersonal stressors and adjustment among early and middle adolescents. Journal Adolescence Health, 2006, Apr, 38 (4), 409-15.

WHO, International Health Conference, Preamble to the Constitution of the World Health Organization as adopted by the International Health Conference, New York, 19-22 June, 1946; signed on 22 July 1946 by the representatives of 61 States (Official Records of the World Health Organization, no. 2, p. 100) and entered into force on 7 April 1948.

How to cite this article: J Kamble, A Pathak (2016), Stress and Its Association with Health and Well Being, International Journal of Indian Psychology, Volume 3, Issue 3, No. 6, DIP: 18.01.107/20160303 